MR AWAIS WAHAB (Orcid ID : 0000-0001-6716-8113)

Article type : Review Article

\title{
The budding and depth of invasion model in oral cancer - a systematic review and meta-analysis
}

\author{
Awais Wahab ${ }^{a}$, Oona Onkamob, Matti Pirinenc, Alhadi Almangush ${ }^{\text {d, }}$, Tuula Salo ${ }^{\mathrm{e}}$
}

${ }^{a}$ Department of Pathology, University of Helsinki, Helsinki, Finland. Department of Oral and Maxillofacial Diseases, University of Helsinki, Helsinki, Finland.

email: awais.wahab@helsinki.fi 
Research Program in Systems Oncology, Faculty of Medicine, University of Helsinki, Helsinki, Finland. University of Turku, Institute of Biomedicine, Pathology, Turku, Finland

Faculty of Dentistry, University of Misurata, Misurata, Libya.

email: alhadi.almangush@helsinki.fi

e Department of Oral and Maxillofacial Diseases, University of Helsinki, Helsinki, Finland.

Cancer and Translational Medicine Research Unit, Medical Research Center Oulu, University of Oulu and Oulu University Hospital, Oulu, Finland.

email: tuula.salo@helsinki.fi

Corresponding Author: Professor Tuula Salo, DDS, PhD

Department of Oral and Maxillofacial Diseases, University of Helsinki, Finland

email: tuula.salo@helsinki.fi

Phone: +358 405441560

Disclosure: The authors declare no conflicts of interest.

Acknowledgment This study was supported by a grant from the Helsinki University Hospital Research Fund, The Sigrid Juselius Foundation, and The Cancer Society of Finland.

\section{ABSTRACT}

This article is protected by copyright. All rights reserved 
Background: Tumour budding (B) and depth of invasion (D) have both been reported as promising prognostic markers in oral squamous cell carcinoma (OSCC). This meta-analysis assessed the prognostic value of the tumour budding and depth of invasion combination (BD model) in OSCC.

Methods: Databases including OvidMedline, PubMed, Scopus, and Web of Science were searched for articles that studied the BD model as a prognosticator in OSCC. PICO search strategy was "In OSCC patients, does BD model have a prognostic power?" We used the reporting recommendations for tumour marker prognostic studies (REMARK) criteria to evaluate the quality of studies eligible for systematic review and meta-analysis.

Results: Nine studies were relevant as they analysed the BD model for prognostication of OSCC. These studies used either haematoxylin and eosin (HE) or Pan-Cytokeratin (PCK) stained resected sections of OSCC. Our meta-analysis showed a significant association of BD model with OSCC disease free survival (hazard ratio $=2.02 ; 95 \%$ confidence interval $=1.44-2.85$ ).

Conclusions: The BD model is a simple and reliable prognostic indicator for OSCC. Evaluation of the BD model from HE- or PCK-stained sections could facilitate individualized treatment planning for OSCC patients.

Keywords: oral squamous cell carcinoma, tumour budding, depth of invasion, BD model, prognostication, survival analysis.

\section{Introduction}

Globally, oral squamous cell carcinoma (OSCC) constitutes $4.7 \%$ to $20.3 \%$ of all head and neck malignancies (Chen et al. 2016; Siegel, Miller, \& Jemal, 2017) and has less than 50\% 5-year overall survival rate (Kim et al. 2016). Patients with recurrent OSCC have reduced survival rates even with early-stage disease, as $20 \%$ to $40 \%$ of the patients have occult cervical lymph node metastasis (Bittar, Ferraro, Ribas, \& Lehn, 2016; Safi et al. 2017).

This article is protected by copyright. All rights reserved 
Treatment planning in OSCC is usually based on the cTNM classification and tumour histological grade (El-Naggar, Chan, Grandis, Takata, \& Slootweg, 2017). However, several studies have highlighted shortcomings of the WHO histologic grade classification in predicting the prognosis of OSCC patients (Almangush et al. 2015; Brierley, Gospodarowicz, \& Wittekind, 2017; Müller, 2017). In addition, disease progression and treatment response still differ conspicuously among patients with a similar cTNM stage (Lindenblatt et al. 2012; Low, Gao, Elliott, \& Clark, 2015; Sawazaki-Calone et al. 2015). Therefore, it is crucial to identify more credible prognostic models based on histological features of the tumour to develop more appropriate treatment plans for OSCC patients. Almangush and colleagues first introduced the prognostic BD score for OSCC, which consists of the histological parameters tumour budding (B) and depth of invasion (D), (Almangush et al. 2015).

Tumour budding is defined as fewer than five cancer cells forming a cell cluster(s) at the invasive front of the tumour (Kadota et al. 2015; Rogers et al. 2016). Tumour budding has been shown to correlate with epithelial to mesenchymal transition (EMT) in many carcinomas, including tongue cancer (Wang et al. 2011; Liang et al. 2013). In addition, tumour budding is a risk factor for a late neck recurrence (Hori et al. 2017). Depth of invasion (D) is defined as a measurement from the basement membrane zone to the deepest point of cancer cell invasion (Berdugo et al. 2019). In the recent $8^{\text {th }}$ edition of the American Joint Committee on Cancer (AJCC) classification, Depth of invasion has been added into the TNM staging of the tumour to improve its prognostic value (Amin et al. 2017).

Many studies have reported on the prognostic value of the BD model in cancers from different subsites of the oral cavity (Almangush et al. 2015; Sawazaki-Calone et al. 2015; Seki et al. 2016; Strieder et al. 2017; Hori et al. 2017; Yu et al. 2019). These publications highlighted the future prospect of considering BD scores in treatment planning of OSCC. Our hypothesis was to validate through pooled analyses of the published studies whether BD model has a significant prognostic value in OSCC. Therefore, this study aimed to systematically review the literature to retrieve all publications related to the $\mathrm{BD}$ model in OSCC and to conduct a meta-analysis of the eligible studies.

This article is protected by copyright. All rights reserved 


\section{Methods}

Search Protocol: Two independent reviewers A.W and O.O conducted the systematic review.

The databases of OvidMedline, PubMed, Scopus, and Web of Science were searched using the following keywords: ('oral' or 'mouth' or 'tongue' or 'floor of mouth' or 'lip' or 'gingiva' or 'buccal' or 'palate') AND ('cancer' OR 'carcinoma' OR 'neoplasm' OR 'tumor' OR 'tumour') AND ('bd' OR 'bd model' OR 'budding and depth' OR 'budding and depth of invasion'). The PICO question was formulated as follows: "In OSCC patients, does BD model have a prognostic power?"

Studies in English language that evaluated BD model in cohorts of OSCCs were included in our systematic review. Studies in other languages or studies which did not present BD model analysis in OSCC were excluded. References of all relevant articles were also manually searched to ensure inclusion of all eligible studies. Studies on animal samples, and conference abstracts were also excluded. The end point of the search was February 2020. RefWorks software was used to manage records and the data.

Combination of tumour budding (B) and depth of invasion (D): The BD model is originally based on the following three scores: 0,1 , and 2 (Almangush et al. 2015). A tumour with a depth of invasion $<4 \mathrm{~mm}$ and fewer than five buds of carcinoma cells at the invasive front is considered low risk and scored ' 0 '. A tumour with depth of invasion $\geq 4 \mathrm{~mm}$ and with fewer than five buds at the invasive front, or a superficial tumour with $<4 \mathrm{~mm}$ depth of invasion but with five or more buds at the invasive front is considered at intermediate risk and scored ' 1 '. A tumour with depth of invasion $\geq 4$ $\mathrm{mm}$ and with five or more buds is considered high risk and scored '2' (Figure 1. Copyright (2016) Wiley. Used with permission from Strieder et al. Comparative analysis of three histologic grading methods for squamous cell carcinoma of the lip, Oral Diseases, John Wiley and Sons).

Quality Assessment: The reporting recommendations for tumour marker prognostic studies (REMARK) guidelines (Altman, McShane, Sauerbrei, \& Taube, 2012) were followed to assess the quality of studies that evaluated the prognostic value of the BD model in OSCC. The guidelines for systematic review and meta-analysis of prognostic factor studies were followed (Riley et al. 2019)

This article is protected by copyright. All rights reserved 
along with the preferred reporting items for systematic review and meta-analysis protocols (PRISMAP), (Moher et al. 2015).

Statistical Methods: The statistical software R (version 3.4.0) was used to run the 'meta' package (version 4.8-1) for meta-analysis. For each analysis, both an inverse variance weighted fixed effect analysis was performed. The random effect model analysis was considered as the main result to account for possible heterogeneity among studies (Higgins \& Thompson, 2002). In addition to metaanalysed effect sizes, we also included the estimated proportion of variation in effect sizes due to heterogeneity $\left(I^{2}\right)$.

\section{Results}

Search Results: A total of 396 hits were retrieved from databases. There were 116 duplicates that were deleted and 280 studies were included for further analyses (Figure 2). Out of these, nine studies related to the BD model in OSCC were included in this systematic review. Among these, three studies were from Japan, one from Finland, two had cases from both Finland and Brazil, two were from Brazil, and one was from China. In Table 1, each study is reported with the total number of cases, TNM stage, oral subsite, primary treatment, follow-up time, staining method/s used, cut-off point for budding and depth of invasion, survival or sensitivity and specificity analyses, hazard ratio (HR), and $P$ value.

\section{Meta-analysis of disease-free survival:}

Only four studies reported detailed statistical analyses for disease-free survival (DFS), including HRs and $95 \%$ confidence intervals (CI); these studies were included in the meta-analysis visualized using forest plots (Figure 3, a and b).

The first forest plot (Figure 3a) included all multivariate results of BD as the predictor of interest and DFS as the response variable $(\mathrm{HR}=2.02,95 \% \mathrm{CI}=1.44-2.85)$. In the second forest plot (Figure $3 \mathrm{~b})$, both multivariate and univariate analyses that reported HR values for BD as the predictor and DFS as the response variable were combined to attain cumulative effect size $(\mathrm{HR}=1.82,95 \% \mathrm{CI}=1.44$ - 
2.29). The results of the meta-analysis did not present any heterogeneity $\left(I^{2}=0\right)$. Funnel plots were employed to evaluate bias across studies with HR as the effect estimate and standard error as the measure of precision. In the funnel plots (Figure 4, a and b), the effect estimates were within the expected $95 \%$ region marked by the diagonal segments and neither funnel plot indicated a bias.

\section{Association of the BD model with disease-specific survival and overall survival:}

Although the published results (Table 1) on the association of BD model with disease-specific survival (DSS) and overall survival (OS) were not enough to conduct meta-analyses, there was some evidence indicating a promising prognostic value for the $\mathrm{BD}$ model in prediction of these two survival outcomes. For example, Almangush et al. (2015) revealed a significant association of the BD model with DSS of OTSCC patients (HR $=5.11,95 \%$ CI $2.05-12.75$; $\mathrm{P}<0.001)$. In contrast to other parameters WHO grading system, histological risk (HR) model and malignancy grading of the deep invasive margins $(\mathrm{MG})$, only the BD model correlated with DSS $(\mathrm{P}=0.009)$ in a study by SawazakiCalone et al. (2015). Overall survival (OS) is significantly associated with both budding and tumour depth of invasion $(\mathrm{P}<0.05)$ in Seki et al. (2016). These results were similar to those observed by Strieder et al. (2017), where OS was also associated with the BD model $(\mathrm{P}=0.045)$. Similarly, $\mathrm{Yu}$ et

al. (2019) demonstrated that BD score associated with OS (HR $=2.77,95 \%$ CI $1.78-4.33$; P < $0.001)$.

\section{Association of the BD model with clinicopathological factors:}

A significant association $(P<0.001)$ of the BD model with histological risk (HR) model was demonstrated by Sawazaki-Calone et al. (2015) and Seki et al. (2016), who reported 100\% sensitivity for tumour budding ( $>3)$ and tumour depth of invasion $(>3 \mathrm{~mm}$ ) for neck metastasis (Seki, Sano, Yokoo, \& Oyama, 2016). A strong association was also reported between neck recurrence and the BD model with $89 \%$ sensitivity and $95 \%$ specificity by Hori et al. (2017). A recent publication (Hori et al. 2020) revealed an association between neck recurrence and the $\mathrm{BD}$ model $(\mathrm{HR}=5.46,95 \% \mathrm{CI} 1.08$ 27.52; $\mathrm{P}<0.05)$. Yu et al. (2019) observed that $\mathrm{T}$-stage $(\mathrm{P}=0.002)$, lymph node metastasis $(\mathrm{P}<$ 0.001), clinical stage $(\mathrm{P}<0.001)$, invasive pattern $(\mathrm{P}<0.001)$, Glasgow Microenvironment Score

This article is protected by copyright. All rights reserved 
(GMS) $(\mathrm{P}=0.031)$, and tumour-to-stroma percentage $(\mathrm{P}=0.006)$ were all associated significantly with BD scores.

\section{Discussion}

This study aimed to meta-analyse the prognostic significance of BD model in studies of OSCC. It was hypothesized that $\mathrm{BD}$ model has a prognostic role in OSCC. For this purpose, databases were searched to gather studies of BD model for a systematic review and meta-analysis.

The recent WHO classification of head and neck tumours pointed out that the conventional histological grading (well, moderate, or poorly differentiated OSCC) correlates poorly with clinical outcome and a non-cohesive pattern of invasion, perineural and lymphovascular invasion, bone invasion, and tumour thickness of $\geq 4 \mathrm{~mm}$ is associated with poorer prognosis (El-Naggar et al. 2017). The histological grading system is easier to analyse and is therefore still widely used in clinical pathology reports. However, this system has been widely criticized by several authors (Müller, 2017; Brierley et al. 2017). Here, our meta-analysis revealed that readily available BD score is significantly associated with DFS as an independent prognostic indicator. Additionally, in many studies a number of clinicopathological factors (such as T-stage, lymph node metastasis, clinical stage, invasive pattern) and both of OS and DSS of OSCC patients were significantly associated with the BD model.

In our systematic review, all the studies used surgery as primary treatment. Some studies presented significant results of the BD model for OSCC in OS: ( $\mathrm{HR}=2.77,95 \% \mathrm{CI} 1.78-4.33$; $\mathrm{P}<0.001)$, ( $\mathrm{Yu}$ et al. 2019), and DSS: (HR= 5.11,95\% CI 2.05-12.75; $\mathrm{P}<0.001)$ (Almangush et al. 2015; $\mathrm{Yu}$ et al. 2019). Specificity of $93 \%$ and $96.9 \%$ for BD model was presented by Hori et al. (2017) and Almangush et al. (2018) respectively. However, the published studies were insufficient to conduct meta-analyses on OS or DSS. Four original studies had appropriate statistics for meta-analyses of DFS. To avoid bias due to potential heterogeneity, a random-effect model (in addition to a fixedeffect model) was employed to combine heterogenous studies (Guolo \& Varin, 2015). However, as we did not detect any heterogeneity, therefore the random-effect model produced the same results as the fixed-effect model. We conducted two meta-analyses (Fig. 3), one with HR values from the three

This article is protected by copyright. All rights reserved 
multivariate analyses for DFS (Almangush et al. 2015; Sawazaki-Calone et al. 2015; Hori et al. 2020) (Fig. 3a), and the other that also included one additional study (Yu et al. 2019) that provided only univariate analysis results for DFS (Fig. 3b). Both forest plots indicated significant meta-analysed HR values and thus validated the results of the studies that presented prognostic results of the BD model in DFS of OSCC patients. Based on these analyses, the BD model was shown to be a prognostic indicator for DFS in OSCC, which was consistent across these studies. Of note, tongue was the oral subsite in most of the included studies. However, inclusion of different subsites along with different stages in the meta-analysis were reported and are among the limitations. Despite these shortcomings, the gathered evidence was sufficient to propose that a high BD score is an indicator for poor prognosis in OSCC.

In the literature, tumour budding has been analysed in at least 10 studies of OSCC (Jensen et al. 2015; Angadi et al. 2015; Almangush et al. 2015; Manjula, Augustine, Selvam, \& Mohan, 2015; Xie et al. 2015; Seki et al. 2016; Boxberg et al. 2017; Pedersen et al. 2017; Hori et al. 2017; Arora et al. 2017). The cut-off point of five buds was advocated in most of these studies, and only one group (Seki et al. 2016) adjusted the cut-off point of three buds. Budding represents two malignant features, namely discohesion of cells and active invasion. Therefore, tumour budding has been considered as characteristic behaviour of an aggressive tumour (Wang et al. 2011). Recently, a study presented tumour budding and worst pattern of invasion to be an important risk factors to predict lymph node metastasis in all stages of OSCC (Chatterjee et al, 2019). Outside the oral cavity, tumour budding is associated with poor prognosis in several other malignancies, such as bladder, cervical, rectal, breast, cutaneous, and hepatocellular cancers (Fukumoto et al. 2016; Huang, Cai, Xu, Guo, \& Wang, 2016; Jäger et al. 2018; Lino-Silva, Salcedo-Hernández, \& Gamboa-Domínguez, 2018; Voutsadakis, 2018 ; Wei et al. 2020).

Depth of invasion has predictive value for lymph node metastasis and loco-regional recurrence in OSCC (Shinn et al. 2018). In our review, six of the studies set a cut-off point of $4 \mathrm{~mm}$ (Sawazaki-Calone et al. 2015; Almangush et al. 2015; Strieder et al. 2017; Almangush et al. 2018a; Almangush et al. 2018b; Yu et al. 2019), and in three Japanese studies (Seki et al. 2016; Hori et al. 2017, 2020) the cut-off point for depth of invasion was adjusted at $3 \mathrm{~mm}$. The latest cancer staging 
manual of the AJCC ( $8^{\text {th }}$ edition) considers depth of invasion in the TNM classification system (Amin et al. 2017). This addition into the TNM classification already improves the predictive value and stratification of different TNM stages, including recognition of low-risk patients with a reduced survival rate (Rodrigues et al. 2020).

The BD score is relatively simple for objective analysis (Sawazaki-Calone et al. 2015) and as it is possible to evaluate even from the originally HE-stained slides, the analyses are inexpensive and the score can easily be added to clinical pathology reports. In contrast, the other histological models, such as malignancy grading of the deep invasive margins (MG), (Bryne, Koppang, Lilleng, \& Kjaerheim, 1992) and histological risk (HR) model (Brandwein-Gensler et al. 2005) are more difficult to apply (Bundgaard et al. 2002; Gueiros, Coletta, Kowalski, \& Lopes, 2011; Lindenblatt et al. 2012). To the best our knowledge, this is the first systematic review and meta-analysis on the prognostic value of BD model in OSCC.

\section{Conclusion}

In this systematic review, we found a total of nine studies that all presented significance of BD model as a prognosticator in OSCC. Based on the current meta-analysis, we here conclude that the BD model has a strong prognostic power for DFS in OSCC patients. In the future, other practical histopathological models, such as tumour-to-stroma ratio and tumour infiltration lymphocytes, combined with BD score, should be tested to possibly upgrade the prognostic power of histopathological features in OSCC.

\section{Figure Legends}

Figure 1: Budding and Depth of invasion model: (a) Buds or islands of tumour invasion with $<5$ cells $(100 \mu \mathrm{m})$. (b) Length of the tumour area with greatest depth of invasion $\geq 4 \mathrm{~mm}$. 
Copyright (2016) Wiley. Used with permission from (Strieder et al. Comparative analysis of three histologic grading methods for squamous cell carcinoma of the lip, Oral Diseases, John Wiley and Sons).

Figure 2: Flow diagram outlining the search strategy and the search results along various steps.

Figure 3: Forest plots for the pooled analyses of the studies that evaluated the prognostic value of the BD model in assessing DFS of OSCC. (a) All multivariate studies. (b) Multivariate and univariate results combined to obtain the cumulative result of meta-analysis.

(Few confidence limits are marginally different from the original values due to the rounding of hazard ratios and confidence limits to two digits).

Figure 4: Funnel plots constructed to assess overall effect. (a) All multivariate studies (b) All multivariate studies and one univariate study.

\section{Authors contribution}

A.W designed the project, carried out the systematic review, run the meta-analysis, interpreted results, and wrote the manuscript. O.O carried out the systematic review, validated the systematic review, interpreted results, and wrote the manuscript. M.P run the meta-analysis, evaluated, interpreted, validated the meta-analysis, and wrote the manuscript. A.A designed the project, validated the systematic review, validated the meta-analysis, interpreted results, wrote the manuscript, and supervised the project. T.S designed the project, validated the systematic review, validated the meta-analysis, interpreted results, wrote the manuscript, and supervised the project.

\section{References}

This article is protected by copyright. All rights reserved 
Table 1: Summary of studies that examined the prognostic value of BD model in OSCC

\begin{tabular}{|c|c|c|c|c|c|c|c|c|c|c|c|c|}
\hline $\begin{array}{l}\text { Authors, } \\
\text { year } \\
\text { (Country) }\end{array}$ & $\begin{array}{l}\text { No. } \\
\text { of } \\
\text { cases }\end{array}$ & $\begin{array}{l}\text { TNM } \\
\text { stage }\end{array}$ & $\begin{array}{l}\text { Oral } \\
\text { subsite }\end{array}$ & $\begin{array}{l}\text { Primary } \\
\text { treatment }\end{array}$ & Follow-up & $\begin{array}{l}\text { Staining } \\
\text { method }\end{array}$ & $\begin{array}{l}\text { Cutoff } \\
\text { for } \\
\text { budding }\end{array}$ & $\begin{array}{l}\text { Cutoff } \\
\text { for } \\
\text { depth }\end{array}$ & $\begin{array}{l}\text { Survival } \\
\text { Analysis/ } \\
\text { Sensitivity, } \\
\text { Specificity }\end{array}$ & HR (95\% CI) & $P$ value & $\begin{array}{c}\text { REMARK } \\
\text { Quality of } \\
\text { studies }\end{array}$ \\
\hline \multirow{2}{*}{$\begin{array}{l}\text { Almangush } e t \\
a l, \\
2015 \\
\text { (Finland and } \\
\text { Brazil) }\end{array}$} & \multirow[t]{2}{*}{311} & \multirow[t]{2}{*}{$\begin{array}{l}\text { T1- } \\
\text { 2N0 }\end{array}$} & \multirow[t]{2}{*}{ Tongue } & \multirow[t]{2}{*}{ Surgery } & \multirow[t]{2}{*}{57 months } & \multirow[t]{2}{*}{ H-E } & \multirow[t]{2}{*}{5 buds } & \multirow[t]{2}{*}{$4 \mathrm{~mm}$} & DSS & $\begin{array}{l}6.24(2.59-15.04) \\
5.11(\mathbf{2 . 0 5 - 1 2 . 7 5 )}\end{array}$ & $\begin{array}{l}<0.001 \\
<\mathbf{0 . 0 0 1}\end{array}$ & \multirow[b]{2}{*}{7} \\
\hline & & & & & & & & & DFS & $\begin{array}{l}2.14(1.22-3.74) \\
\mathbf{2 . 1 9}(\mathbf{1 . 2 0 - 4 . 0 0 )}\end{array}$ & $\begin{array}{l}0.025 \\
\mathbf{0 . 0 3 3}\end{array}$ & \\
\hline \multirow{3}{*}{$\begin{array}{l}\text { Sawazaki- } \\
\text { Calone et al, } \\
2015 \\
\text { (Brazil) }\end{array}$} & \multirow[t]{3}{*}{113} & \multirow[t]{3}{*}{$\begin{array}{l}\text { T1-T4, } \\
\text { N0, N+ }\end{array}$} & \multirow[t]{3}{*}{$\begin{array}{l}\text { Oral } \\
\text { cavity }\end{array}$} & \multirow{3}{*}{$\begin{array}{l}\text { Surgery, surgery } \\
\text { + postoperative } \\
\text { RT, surgery + } \\
\text { postoperative } \\
\text { RT+CT }\end{array}$} & \multirow[t]{3}{*}{5 years } & \multirow[t]{3}{*}{ H-E } & \multirow[t]{3}{*}{5 buds } & \multirow[t]{3}{*}{$4 \mathrm{~mm}$} & DSS & DSS in 5 yrs $32 \%$ & 0.009 & \multirow[t]{3}{*}{6} \\
\hline & & & & & & & & & DFS & $\begin{array}{l}\text { 1.93 (1.23-3.00) } \\
\text { DFS in } 5 \text { yrs } 49 \%\end{array}$ & $\begin{array}{l}\mathbf{0 . 0 0 3} \\
0.005\end{array}$ & \\
\hline & & & & & & & & & HRS & & $<0.001$ & \\
\hline \multirow{2}{*}{$\begin{array}{l}\text { Seki et al, } \\
2016 \\
\text { (Japan) }\end{array}$} & \multirow[t]{2}{*}{91} & \multirow[t]{2}{*}{$\mathrm{T} 1-\mathrm{T} 4$} & \multirow{2}{*}{$\begin{array}{l}\text { Tongue } \\
\text { and } \\
\text { floor of } \\
\text { mouth }\end{array}$} & \multirow{2}{*}{$\begin{array}{l}\text { Surgery, } \\
\text { preoperative } \\
\text { CT }\end{array}$} & \multirow{2}{*}{$\begin{array}{l}4 \text { months }- \\
5 \text { years }\end{array}$} & \multirow[t]{2}{*}{ IHC } & \multirow[t]{2}{*}{$>3$ buds } & \multirow[t]{2}{*}{$>3 \mathrm{~mm}$} & OS & & $<0.05$ & \multirow[b]{2}{*}{6} \\
\hline & & & & & & & & & Sensitivity & $100 \%$ sensitivity & $<0.05$ & \\
\hline
\end{tabular}

This article is protected by copyright. All rights reserved 


\begin{tabular}{|c|c|c|c|c|c|c|c|c|c|c|c|c|}
\hline 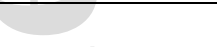 & & & & & & & & & & $>3 \mathrm{~mm}$ budding & & \\
\hline $\begin{array}{l}\text { Strieder et al, } \\
2017 \\
\text { (Brazil) }\end{array}$ & 53 & $\begin{array}{l}\mathrm{T} 1-\mathrm{T} 4, \\
\mathrm{~N} 0, \mathrm{~N}+\end{array}$ & Lip & $\begin{array}{l}\text { Surgery, } \\
\text { surgery + RT }\end{array}$ & $\begin{array}{l}57.5 \text { months } \\
\text { (T1/T2), } \\
159.4 \\
\text { months } \\
\text { (T3/T4) }\end{array}$ & H-E & 5 buds & $4 \mathrm{~mm}$ & $\begin{array}{l}\text { OS } \\
(5 \text { years })\end{array}$ & $75 \%$ (high risk cases) & 0.045 & 6 \\
\hline $\begin{array}{l}\text { Hori et al, } \\
2017 \\
\text { (Japan) }\end{array}$ & 48 & $\begin{array}{l}\text { cT1/2 } \\
\text { N0M0 }\end{array}$ & Tongue & Surgery & 71 months & H-E & 5 buds & $>3 \mathrm{~mm}$ & $\begin{array}{l}\text { Sensitivity } \\
\text { Specificity }\end{array}$ & $\begin{array}{l}89 \% \text { Sensitivity } \\
95 \% \text { Specificity } \\
80 \% \text { PPV } \\
97 \% \text { NPV }\end{array}$ & & 6 \\
\hline $\begin{array}{l}\text { Almangush } e t \\
\text { al, } \\
2018 \mathrm{a} . \\
\text { (Finland and } \\
\text { Brazil) }\end{array}$ & 224 & $\begin{array}{l}\text { T1- } \\
2 \mathrm{~N} 0\end{array}$ & Tongue & Surgery & NA & H-E & 5 buds & $4 \mathrm{~mm}$ & DSS & $\begin{array}{l} \\
\mathbf{1 1 . 6 3}(\mathbf{3 . 8 3}-\mathbf{3 5 . 3 1}) \\
10.43(3.51-31.01)\end{array}$ & $\begin{array}{l} \\
<0.001 \\
<0.001\end{array}$ & 8 \\
\hline $\begin{array}{l}\text { Almangush } e t \\
\text { al, } \\
2018 \mathrm{~b} \\
\text { (Finland) }\end{array}$ & 100 & NA & Tongue & Surgery & $\mathrm{NA}$ & H-E & 5 buds & $4 \mathrm{~mm}$ & Specificity & $\begin{array}{l}96.9 \% \text { (95\% CI 89.3- } \\
99.6 \%)\end{array}$ & $\begin{array}{l}\text { Chi- square } \\
\text { test } \\
<0.001\end{array}$ & 6 \\
\hline $\begin{array}{l}\text { Yu et al, } \\
2019 \\
\text { (China) }\end{array}$ & 246 & $\begin{array}{l}\text { T1- } \\
\text { T2/ } \\
\text { T3-T4 }\end{array}$ & Tongue & Surgery & 60 months & H-E & 5 buds & $4 \mathrm{~mm}$ & DFS & $\mathrm{BD}, 1.66(1.21-2.27)$ & 0.002 & 8 \\
\hline
\end{tabular}

This article is protected by copyright. All rights reserved 


\begin{tabular}{|c|c|c|c|c|c|c|c|c|c|c|c|c|}
\hline Hori et al, & 62 & T1- & & Surgery & 68 months & H-E and & 5 buds & $>3 \mathrm{~mm}$ & DFS & BD, $2.06(0.64-6.57)$ & 0.22 & \\
\hline $\begin{array}{l}2020 \\
\text { (Japan) }\end{array}$ & & $2 \mathrm{~N} 0$ & Tongue & & & PCK & & & $\begin{array}{l}\text { Lymph node } \\
\text { recurrence }\end{array}$ & $\mathrm{BD}, 5.46(1.08-27.52)$ & $<0.05$ & 7 \\
\hline
\end{tabular}

\title{
Notes:
}

a- Values in bold are from multivariate analysis

b- Almangush et al, 2015 and Almangush et al, 2018a are overlapped

c- HR and CI reported by Almangush et al, 2018 were for combined score of tumour-stroma ratio and BD model

d- Hori et al, 2017 and Hori et al, 2020 are overlapped

\author{
Abbreviations: \\ BD: Budding and depth of invasion \\ CI: Confidence interval \\ CT: Chemotherapy \\ DFS: Disease-free survival \\ DSS: Disease-specific survival \\ H-E: Hematoxylin and eosin staining \\ HR: Hazard ratio \\ HRS: Histological risk score \\ iBD: Inflammatory response, Budding and invasion depth \\ IHC: Immunohistochemical staining with cytokeratin or pan-cytokeratin \\ NA: Not available
}

This article is protected by copyright. All rights reserved 
NPV: Negative predictive value

OS: Overall survival

PCK: Pan-Cytokeratin

PPV: Positive predictive value

RT: Radiotherapy

This article is protected by copyright. All rights reserved 

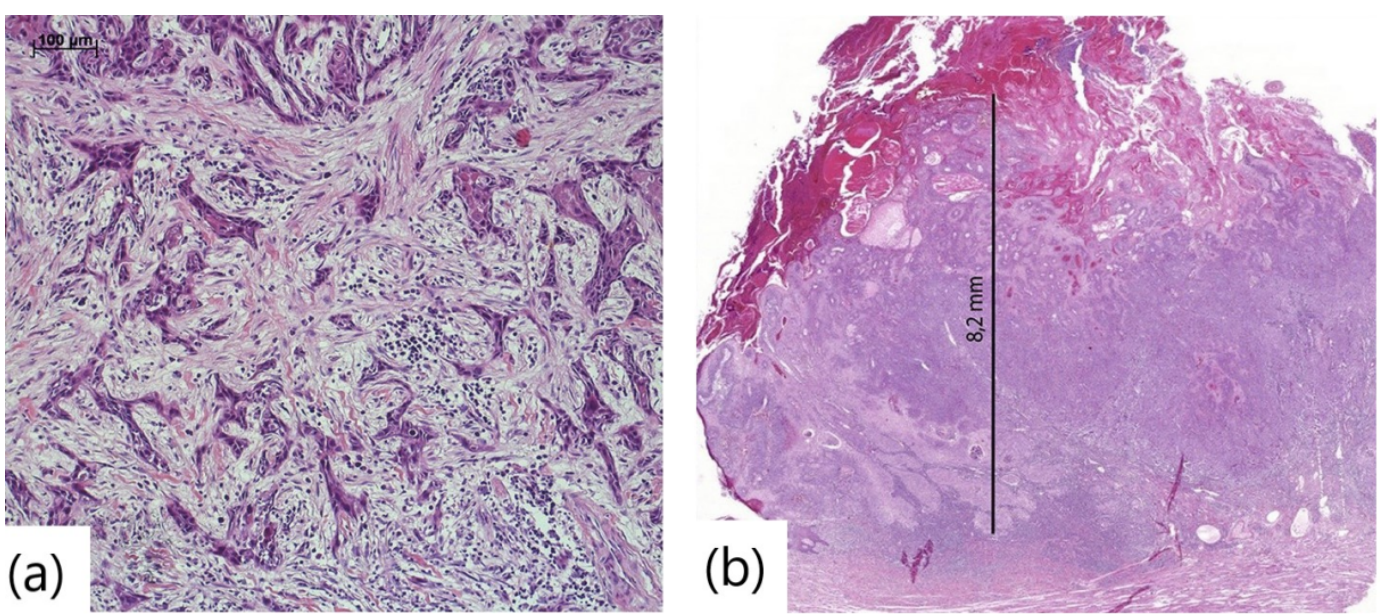

odi_13671_f1.tif

This article is protected by copyright. All rights reserved 


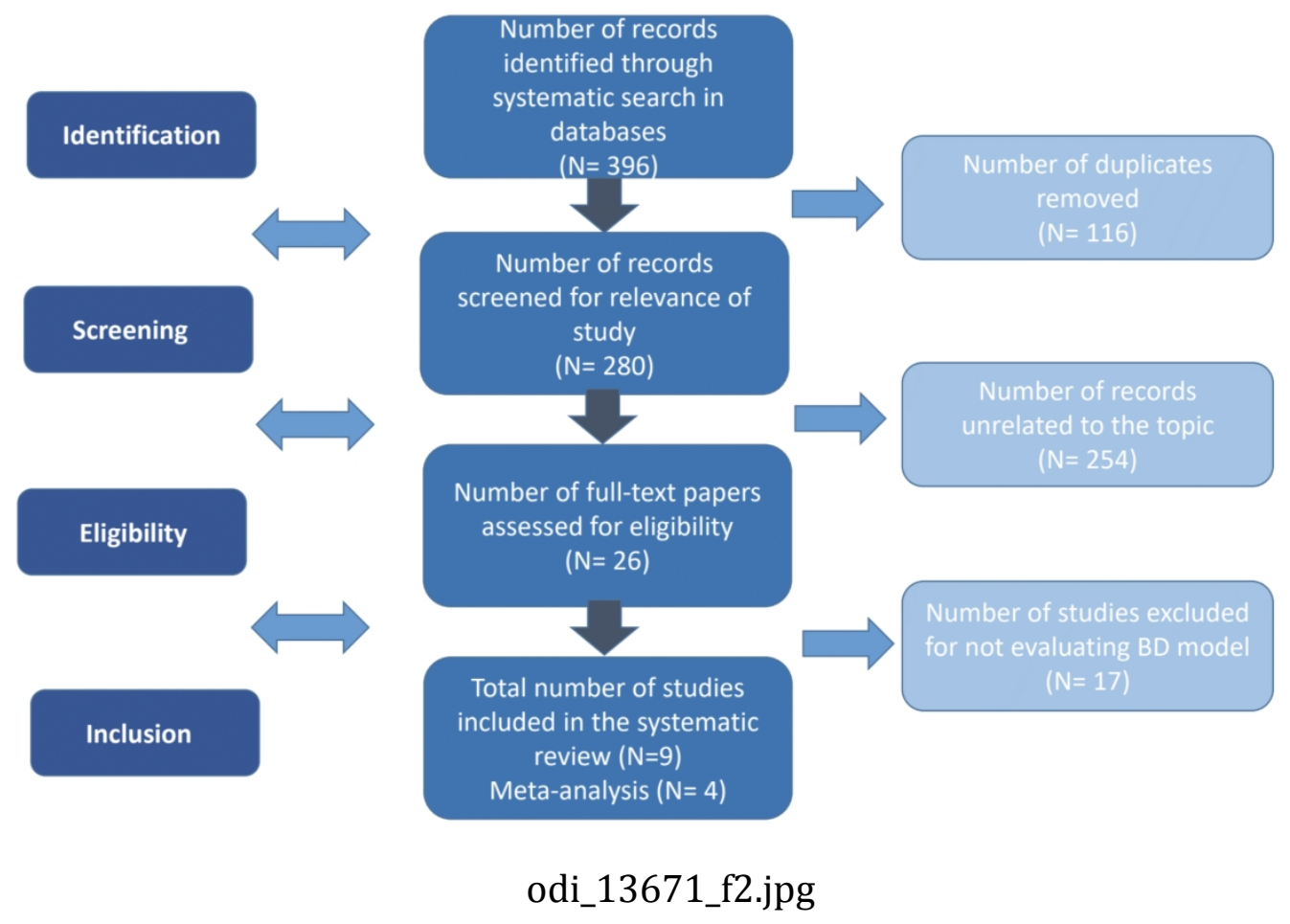

This article is protected by copyright. All rights reserved 


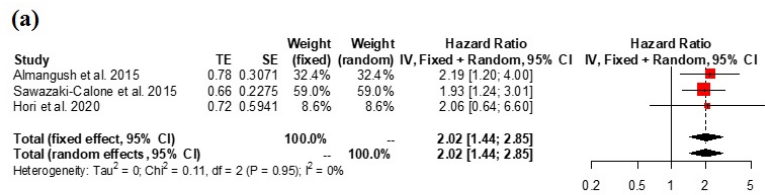

(b)

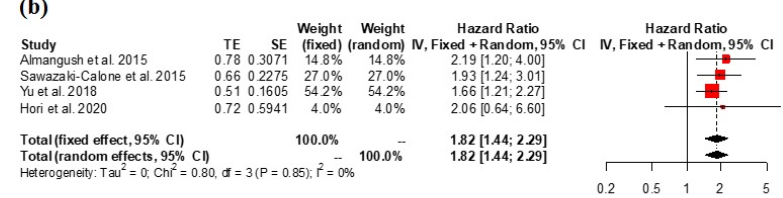

odi_13671_f3.jpg

This article is protected by copyright. All rights reserved 
(a)

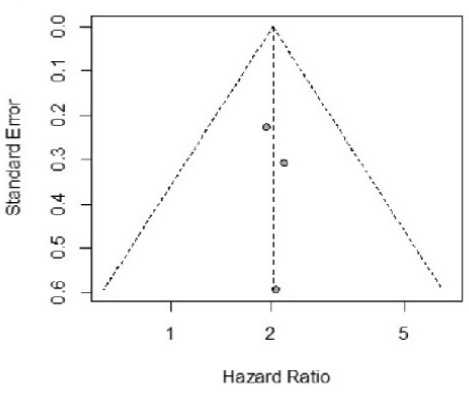

(b)

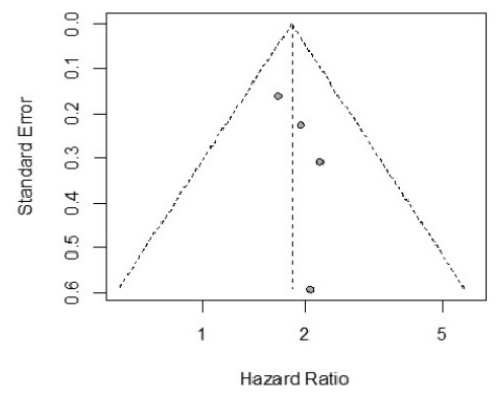

odi_13671_f4.jpg

This article is protected by copyright. All rights reserved 